\title{
OPTIMISATION OF GEOMETRICALLY NON-LINEAR ELASTIC-PLASTIC STRUCTURES IN THE STATE PRIOR TO PLASTIC COLLAPSE
}

\author{
Romanas Karkauskas \\ Dept of Structural Mechanics, Vilnius Gediminas Technical University, \\ Saulètekio al. 11, LT-10223 Vilnius, Lithuania.E-mail: rokark@st.vtu.lt \\ Received 12 March 2007; accepted 28 May 2007
}

\begin{abstract}
A mathematical model and calculation algorithm for geometrically non-linear structure cross-sectional optimisation are developed. Inelastic strains in the state prior to plastic collapse are evaluated. The algorithm is obtained combining the extreme energy principle for minimum value dissipated power and mathematical programming theory in concert with a large displacement analysis. An evaluation of dissipative features by employing inelastic strains finally results in a significant reducement of structure carrying capacity resource versus accounting its elastic response only. The safety requirements of structure involve stability conditions in addition to the strength ones. Stability conditions define the minimum cross-sectional and slenderness values of structural members. An evaluation of the above-mentioned factors restrict a free development of plastic strains, thus an optimal structure generally is in a state prior to plastic failure. The problem is solved iteratively, as the employed values of structural elastic response are functionally related with the optimised parameters ones. During iterative calculus process the design parameters are defined applying the non-linear analysis and the tangent stiffness computational procedures. A simulation of 16-storey steel optimal frame created from standard profiles is presented.
\end{abstract}

Keywords: optimisation, elastic-plastic structure, geometrically non-linearity, geometrical stiffness, tangent stiffness matrix, plastic collapse.

\section{Introduction}

The main aim of different tasks related to optimisation of building structures is to develop an optimal structure with closely related energy inputs and mass. Its behaviour is determined by various external factors and should fit the limit requirements applicable to safety and fitness state. Optimisation of structures manifests itself in the animate nature as well. Structures of living organisms alike building engineering ones are sufficiently strong, rigid and have stable bearing supports. Living organisms have developed their latest structural solutions per course of evolution in continuous fight for existence constantly optimizing the mass of their structural systems to withstand external effects and energy inputs. Thus the quantitative indicators of mass and energy inputs serve the main criteria considered by the nature in development optimal structural systems.

The solution of structural optimisation task is to provide a comprehensive information on its behaviour versus possible work conditions and at any moment of existence. Obviously such a broad perspective cannot facilitate solution of this task employing linear theory methods of structural mechanics. So the principle of small displacements becomes unreliable. Besides, the Hook's law loses its validity at a certain level of stress state for many materials and should be replaced by a nonlinear relation. Thus linear theory assumptions must be abandoned in favour of considerably broader and com- plex generalisations of the non-linear theory. First, one should abandon the calculations for underformed state of structure accounting small displacements. Second, one should assess the influence of changes of structural form and dimensions versus its stress-strain state (SSS). Third, one should employ a non-linear stress-strain relation evaluating the emerging plastic deformations. It is conditioned by extremely large displacements that have been developed in structures prior to plastic collapse. This phenomenon is met in structures produced from certain materials leading to a violation of regular use requirements [1-4]. Thus one must keep in mind the abovementioned situations when developing mathematical models of the structural optimisation problems.

Last three or four decades recognised a rather intensive investigations in development of the structural optimization theory, methods and calculating algorithms; their integration with modern systems of computer modeling and automated design [1-3, 5-13]. Among the most effective methods one can find a methodology of structural optimization joining the mathematical programming theory combined with extreme energy principles and inelastic material response $[2,3,5]$. It became clear that evaluation of parameters of deformed state of a structure and that of material plastic characteristics serves a more precise reflection of its behaviour at various load stages. Thus the latter phenomenon is necessary to evaluate in mathematical models of structural optimisation problems. For this purpose various calculations requirements in 
concert with actual evaluation of behaviour of the structure should be formalised mathematically during all stages of structural deforming. Undoubtedly, it helps develop a more rational design of a structure.

A structure moves to a non-linear behaviour resulting by: firstly, due to large deformations causing rather large displacements; secondly, due to emerging plastic deformations at a limit state reached at certain crosssections. Undoubtedly, optimisation of structures considering non-linear behaviour and inelastic strains is a truly relevant designing problem.

The task of the present investigations is:

- further development of the optimisation problem solution methods, applying extreme dissipated energy principle $[3,5]$ for elastic-plastic geometrically nonlinear structures, evaluating deformed shape influence on structural stiffness;

- peculiarities of development of the tangent stiffness matrix considering various structural changes caused by inner forces;

- analysis of aspects of numerical modelling of the optimization problems.

The proposed techniques are illustrated via solution of sixteen-story single-bay steel frame, subjected by vertical and lateral loads. The optimisation is performed taking into account relations, valid for standard steel cross-sectional properties. One assumes the optimal structure to be in the state prior to plastic failure, resulting from strength and stability constraints. Some structural elements can be in a full plastic state, some partially plastically deformed or in elastic state. The optimisation problem is solved iteratively. Each iteration employs a set of limit moments, have been determined in previous iteration. The optimisation process is continued till certain convergence.

\section{Tangent stiffness method}

\subsection{Evaluation of elastic forces and displacements by the tangent stiffness method}

When large displacements in loaded structure appear, its behaviour is described as the non-linear one, ie strain-displacement relationships contain the non-linear terms. To identify the elastic magnitudes of all internal forces, selected into the vector

$$
\mathbf{S}_{e}=\left(S_{e, j}\right)^{T} \equiv\left(S_{e, 1}, S_{e, 2}, \ldots, S_{e, n}\right)^{T},
$$

and that of the nodal displacements

$$
u_{\mathrm{e}}=\left(u_{e, j}\right)^{T} \equiv\left(u_{e, 1}, u_{e, 2}, \ldots, u_{e, n}\right)^{T},
$$

one must solve the following problem:

$$
\left[K_{\tau}\right] \mathbf{u}=\mathbf{F},
$$

where $\left[K_{\tau}\right]=\left[K_{E}\right]+\left[K_{G}\right]-$ overall tangent stiffness matrix of structure; $\left[K_{E}\right]$ - linear elastic overall stiffness matrix; $\left[K_{G}\right]$-geometric stiffness matrix; $n$-total num- ber of internal member forces of the structure and $m$ is the number of global displacements.

The planar line element a-b is shown in Fig 1. Here values are: displacement components $u_{x}, u_{y}, u_{\varphi}$ and force components $F_{x}, F_{y}, F_{\varphi}$ at its ends.

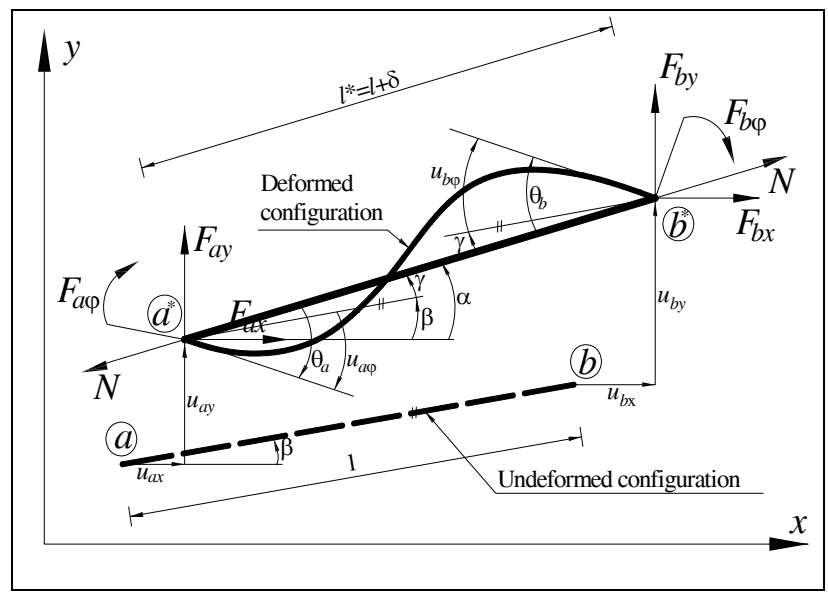

Fig 1. Member end forces and displacements in global coordinates

The fundamental member-forces quantities $M_{a}$, $M_{b}, N$ and distortion quantities $\Theta_{a}, \Theta_{b}, \delta$ are defined in Fig 2.

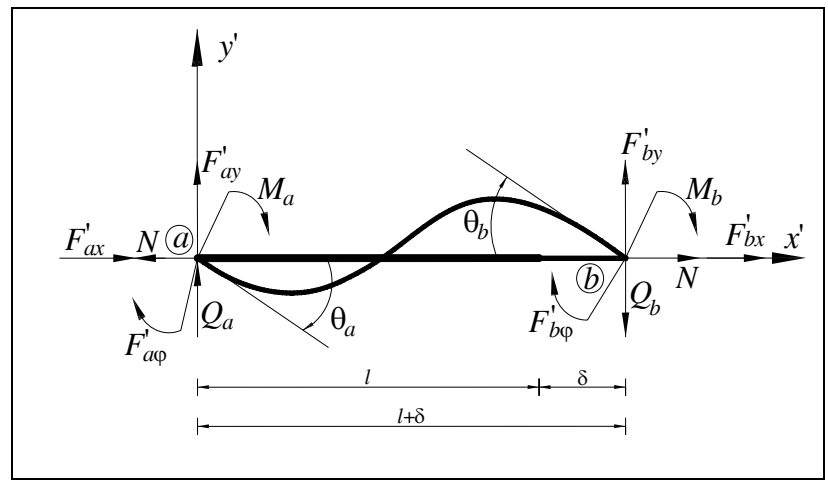

Fig 2. Member local forces and distortions

The governing stiffness non-linear relationship of the end moment-axial forces of the member versus corresponding rotations and changes in the length (flexural and axial distortion) reads $[4,14,15]$ :

$$
\mathbf{S}_{a b}=\left(\left[k_{e, a b}\right]+\left[k_{g, a b}\right]\right) \mathbf{q}_{a b} .
$$

In $\mathrm{Eq}$ (2) the member force vector is $\mathbf{S}_{a b}=\left[M_{a}, M_{b}, N\right]^{T}$ and member distortion vector is $\mathbf{q}_{a b}=\left[\Theta_{a}, \Theta_{b}, \delta\right]^{T}$. The matrices $\left[k_{e, a b}\right]$ and $\left[k_{g, a b}\right]$ are defined as follows: 


$$
\begin{aligned}
& {\left[k_{e, a b}\right]=\left[\begin{array}{ccc}
\frac{4 E I}{l} & \frac{2 E I}{l} & \\
\frac{2 E I}{l} & \frac{4 E I}{l} & \\
& & \frac{E A}{l}
\end{array}\right],} \\
& {\left[k_{g, a b}\right]=\frac{N l}{30}\left[\begin{array}{rrc}
4 & -1 & 0 \\
-1 & 4 & 0 \\
0 & 0 & \frac{E A}{N l \delta}\left(2 \Theta_{a}^{2}-\Theta_{a} \Theta_{b}+2 \Theta_{b}^{2}\right)
\end{array}\right],}
\end{aligned}
$$

where the member axial force is

$$
N=\frac{E A \delta}{l}+\frac{E A}{30}\left(2 \Theta_{a}^{2}-\Theta_{a} \Theta_{b}+2 \Theta_{b}^{2}\right)
$$

Referring to Fig 1, define the local member deformations $\Theta_{a}, \Theta_{b}$ and $\delta$. In global coordinate system it shows the initial undeformed configuration of the member with end coordinates $x_{a}, y_{a}, x_{b}, y_{b}$. After deformation the coordinates possess the positive increments $u_{a x}, u_{a y}, u_{b x}, u_{b y}$. Angle $\alpha$ defines an orientation of deformed configuration of the member $a^{*}-b^{*}$. Then one can find from Fig 1 that

$$
\begin{gathered}
\alpha=\tan ^{-1} \frac{\left(y_{b}+u_{b y}\right)-\left(y_{a}+u_{a y}\right)}{\left(x_{b}+u_{b x}\right)-\left(x_{a}+u_{a x}\right)}, \\
\beta=\tan ^{-1} \frac{y_{b}-y_{a}}{x_{b}-x_{a}}, \quad \gamma=\alpha-\beta, \\
l=\left[\left(x_{b}-x_{a}\right)^{2}+\left(y_{b}-y_{a}\right)^{2}\right]^{1} . \\
l^{*}=\sqrt{\left[\left(x_{b}+u_{b x}\right)-\left(x_{a}+u_{a x}\right)\right]^{2}+\left[\left(y_{b}+u_{b y}\right)-\left(y_{a}+u_{a y}\right)\right]^{2}} .
\end{gathered}
$$

Finally, the local member deformations can be expressed via the global ones by

$$
\begin{gathered}
\Theta_{a}=u_{a \varphi}+\gamma, \\
\Theta_{b}=u_{b \varphi}+\gamma, \\
\delta=l^{*}-l .
\end{gathered}
$$

The derived physical relationship (2) yields the highly non-linear expressions, because they are functions of the member axial force. Hence for computational purposes working in terms of incremental values becomes a necessary condition. To obtain the incremental stiffness relationship it is necessary to differentiate Eq (2) partially, with respect to $\Theta_{a}, \Theta_{b}$ and $\delta$, in turn. Finally one obtains:

$$
\Delta \mathbf{S}_{a b}=\left[\begin{array}{ccc}
\frac{4 E I}{l}+k_{11} & \frac{2 E I}{l}+k_{12} & \frac{E A}{30}\left(4 \Theta_{a}-\Theta_{b}\right) \\
\cdot & \frac{4 E I}{l}+k_{22} & \frac{E A}{30}\left(-\Theta_{a}+4 \Theta_{b}\right) \\
\cdot & \text { symmetric } & \frac{E A}{l}
\end{array}\right] \Delta \mathbf{q}_{a b} .
$$

That is

$$
\Delta \mathbf{S}_{a b}=\left(\left[k_{e, a b}\right]+\left[k_{\Delta, a b}\right]\right)=\left[k_{\Delta}\right] \Delta \mathbf{q}_{a b} .
$$

In Eq (7) the terms of the $\left[k_{\Delta, a b}\right]$ matrix are defined as:

$$
\begin{gathered}
k_{11}=\frac{4 E A}{30} \delta+\frac{E A l}{300}\left(8 \Theta_{a}^{2}-4 \Theta_{a} \Theta_{b}+3 \Theta_{b}^{2}\right) \\
k_{12}=-\frac{E A}{30} \delta+\frac{E A l}{300}\left(-2 \Theta_{a}^{2}+6 \Theta_{a} \Theta_{b}-2 \Theta_{b}^{2}\right) \\
k_{22}=\frac{4 E A}{30} \delta+\frac{E A l}{300}\left(3 \Theta_{a}^{2}-4 \Theta_{a} \Theta_{b}+8 \Theta_{b}^{2}\right)
\end{gathered}
$$

Now one must perform a transformation of member force-distortion relationships to nodal force-displacement relationships. From equilibrium considerations of the member shown in Fig 1, the relationships between the member basic forces and local nodal forces are:

$$
\left[\begin{array}{ccc}
0 & 0 & -1 \\
-1 / l^{*} & -1 / l^{*} & 0 \\
1 & 0 & 0 \\
0 & 0 & 1 \\
1 / l^{*} & 1 / l^{*} & 0 \\
0 & 1 & 0
\end{array}\right]\left[\begin{array}{c}
M_{a} \\
M_{b} \\
N
\end{array}\right]=\left[\begin{array}{c}
F_{a x}^{\prime} \\
F_{a y}^{\prime} \\
F_{a \varphi}^{\prime} \\
F_{b x}^{\prime} \\
F_{b y}^{\prime} \\
F_{b \varphi}^{\prime}
\end{array}\right]
$$

That is,

$$
\left[A_{a b}^{\prime}\right] \mathbf{S}_{a b}=\mathbf{F}_{a b}^{\prime} \text {. }
$$

The incremental local nodal forces $\Delta \mathbf{F}_{a b}^{\prime}$ are obtained by differentiating equilibrium $\mathrm{Eq}$ (10) with respect to both $\mathbf{S}_{a b}$ and $\mathbf{F}_{a b}^{\prime}$ in the usual way. It results:

$$
\Delta \mathbf{F}_{a b}^{\prime}=\left[A_{a b}^{\prime}\right] \Delta \mathbf{S}_{a b}+\left[\Delta A_{a b}^{\prime}\right] \mathbf{S}_{a b}
$$

It is seen that $\left[\Delta A_{a b}^{\prime}\right]$ relates to $\Delta \mathbf{F}_{a b}^{\prime}$ to $\mathbf{S}_{a b}$, when the member possesses an increment of displacements. Thus the member has been rotated slightly and obtains an extension, $\delta$. Therefore

$$
\left[\Delta A_{a b}^{\prime}\right]=\left[k_{g, N}^{\prime}\right]+\left[k_{g, Q}^{\prime}\right]
$$

where: $\left[k_{g, N}^{\prime}\right]$ evaluates the chord rotation effect vs the node force components in the member (influence of the chord rotation on the $x^{\prime}, y^{\prime}$ components vs the axial force $N$ in the member); $\left[k_{g, Q}^{\prime}\right]$ evaluates the influence of the transverse shear $Q$ (Fig 2) which is the result of node forces in the $y^{\prime}$ direction at the ends of the member. The components of these forces will evidently change when the chord possesses the rotation $\Delta \alpha$. For example, small increment of $\Delta u_{a y}, \Delta u_{b y}$ and $\Delta u_{a x}, \Delta u_{b x}$ give:

$$
\left[k_{g, N}^{\prime}\right]=\frac{N l^{2}}{30}\left[\begin{array}{rrrrrr}
0 & 0 & 0 & 0 & 0 & 0 \\
0 & 1 & 0 & 0 & -1 & 0 \\
0 & 0 & 0 & 0 & 0 & 0 \\
0 & 0 & 0 & 0 & 0 & 0 \\
0 & -1 & 0 & 0 & 1 & 0 \\
0 & 0 & 0 & 0 & 0 & 0
\end{array}\right]
$$




$$
\left[k_{g, Q}^{\prime}\right]=\frac{M_{a}+M_{b}}{l}\left[\begin{array}{rrrrrr}
0 & -1 & 0 & 0 & 1 & 0 \\
-1 & 0 & 0 & 1 & 0 & 0 \\
0 & 0 & 0 & 0 & 0 & 0 \\
0 & 1 & 0 & 0 & -1 & 0 \\
1 & 0 & 0 & 0 & -1 & 0 \\
0 & 0 & 0 & 0 & 0 & 0
\end{array}\right] .
$$

As $\left[\Delta A_{a b}^{\prime}\right]$ involves the displacement increments $\Delta \mathbf{u}_{a b}^{\prime}$, one obtains that

$$
\left[\Delta A_{a b}^{\prime}\right] \mathbf{S}_{a b} \rightarrow\left[k_{g, N}^{\prime}\right] \Delta \mathbf{u}_{a b}^{\prime}+\left[k_{g, Q}^{\prime}\right] \Delta \mathbf{u}_{a b}^{\prime} .
$$

The incremental member distortions $\Delta \mathbf{q}_{a b}$ are obtained by transformation $\mathrm{Eq}(10)$, that is

$$
\Delta \mathbf{q}_{a b}=\left[A_{a b}^{\prime}\right]^{T} \Delta \mathbf{u}_{a b}^{\prime} .
$$

Therefore, substituting Eqs (8), (16) and relation (15) into Eq (11), and neglecting the second order term, the incremental equilibrium equations one obtains

$$
\Delta \mathbf{F}_{a b}^{\prime}=\left[A_{a b}^{\prime}\right]\left[k_{\Delta}\right]\left[A_{a b}^{\prime}\right]^{T} \Delta \mathbf{u}_{a b}^{\prime}+\left[k_{g, N}^{\prime}\right] \Delta \mathbf{u}_{a b}^{\prime}+\left[k_{g, Q}^{\prime}\right] \Delta \mathbf{u}_{a b}^{\prime} .
$$

Thus the incremental relation between member nodal forces and displacements (tangent stiffness relationship) in local coordinates can be written as

$$
\Delta \mathbf{F}_{a b}^{\prime}=\left[k_{T}^{\prime}\right] \Delta \mathbf{u}_{a b}^{\prime},
$$

where

$$
\left[k_{T}^{\prime}\right]=\left[A_{a b}^{\prime}\right]\left[k_{\Delta}\right]\left[A_{a b}^{\prime}\right]^{T}+\left[k_{g, N}^{\prime}\right]+\left[k_{g, Q}^{\prime}\right]
$$

will be composed of two parts, ie into elastic stiffness

$$
\left[k_{E}^{\prime}\right]=\left[A_{a b}^{\prime}\right]\left[k_{e, a b}\right]\left[A_{a b}^{\prime}\right]^{T}
$$

and geometrical stiffness

$$
\left[k_{G}^{\prime}\right]=\left[A_{a b}^{\prime}\right]\left[k_{\Delta, a b}\right]\left[A_{a b}^{\prime}\right]^{T}+\left[k_{g, N}^{\prime}\right]+\left[k_{g, Q}^{\prime}\right]
$$

relatively. This is conditioned by the presence of axial force in the member for the load level at the beginning of the increment and the subsequent effects of the geometry changes in their components. Thus the member tangent stiffness matrix $\left[k_{T}^{\prime}\right]$ in local coordinates may be rewritten as

$$
\left[k_{T}^{\prime}\right]=\left[k_{E}^{\prime}\right]+\left[k_{G}^{\prime}\right] .
$$

The transformation from local to global components is now straightforward. Now define the direction cosine matrix $\left[T_{a b}\right]$ in the local axes and obtain the member tangent stiffness matrix in global coordinates

$$
\left[k_{T}\right]=\left[T_{a b}\right]^{T}\left[k_{T}^{\prime}\right]\left[T_{a b}\right] \text {. }
$$

The matrix $\left[k_{T}\right]$ is obtained for each member; these are subsequently assembled to find the system tangent stiffness matrix $\left[K_{\tau}\right]$. The latter matrix is substituted into the incremental equilibrium equations (17). It follows then that

$$
\left[K_{\tau}\right] \Delta \mathbf{u}=\Delta \mathbf{F} .
$$

Here $\Delta \mathbf{u}$ and $\Delta \mathbf{F}$ are the $m$-dimensional vectors of incremental values of nodal displacements and external loads, respectively.
Since the member incremental internal forces are of interest when the effects of stresses on the member yield conditions are being examined, they may be obtained from (8) via the equation

$$
\Delta \mathbf{S}_{a b}=\left[k_{\Delta}\right]\left[A_{a b}^{\prime}\right]^{T}\left[T_{a b}\right] \Delta \mathbf{u}_{a b} .
$$

\subsection{Tangent stiffness method computational procedure}

There are different numerical procedures that can be incorporated in solving of non-linear problems by the finite element method [4, 15]. A successful procedure should possess the following features:

monitoring techniques of the progress of computations along the equilibrium paths of the system;

an iterative method to solve a set of simultaneous non-linear equations ensuring the equilibrium state along the path;

termination schemes to end the solution process.

To solve such a non-linear set of equations (20) we apply the Newton-Raphson iterative method [4, 15] with force control, because the load deflection curve is a convex function. One must remind the reader that the structure is in the state prior to plastic collapse. It yields that the tangent stiffness matrix will be non-zero one: $\left[K_{\tau}\right] \neq 0$. Numerical simulations proved to the final value was achieved in 2 or 3 steps.

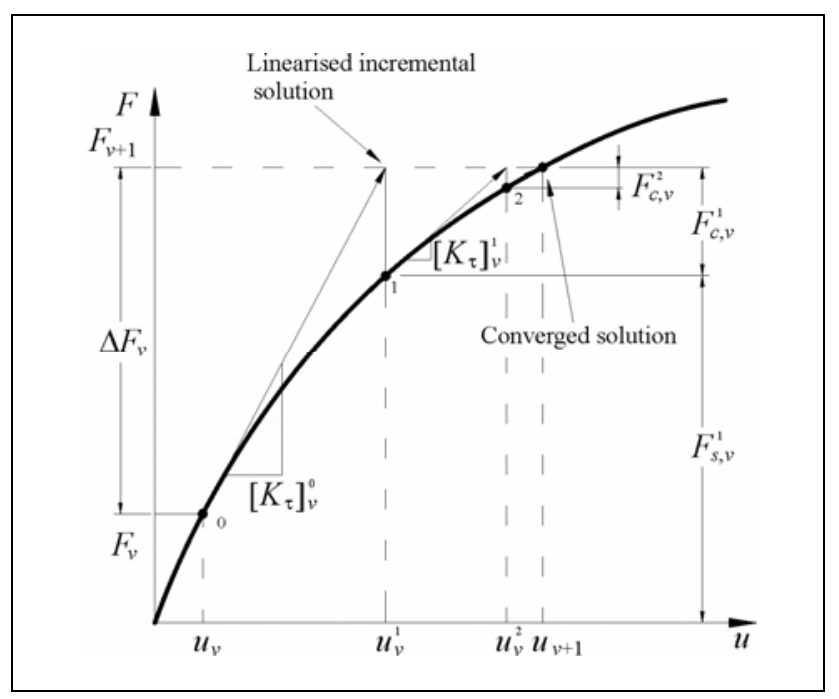

Fig 3. Computational procedure

The computation technique principle is presented in Fig 3. It determines the structure non-linear response values. In this scheme, the loads increment $\Delta F_{v}$ applied to the system are used as the prescribed variables. Applying the Newton-Raphson method for a certain load magnitude $F_{v}$, the iterations $i$ are performed for eliminating the unbalanced (compensating) joint forces $F_{c, v}^{i}$, resulting from unbalance of joint external forces and internal joint forces, ie:

$$
\mathbf{F}_{c, v}^{i}=\mathbf{F}_{v+1}-\mathbf{F}_{s, v}^{i} .
$$


Here:

$\mathbf{F}_{c, v}^{i}-$ the vector of unbalanced joint forces at the end of $i$-th iteration of the current step $v$;

$\mathbf{F}_{v+1}$ - the vector of joint external forces at the end of the step $v . \mathbf{F}_{v+1}$ is kept to be constant during the iterations of this step;

$\mathbf{F}_{s, v}^{i}$ - the vector of joint internal forces at the end of $i$-th iteration of the step $v$.

The aforementioned tolerance appears, when the actual problem is linearised at the considered iteration, ie the tangent stiffness matrix is created for the actual nodal displacements being identified in the previous iteration.

Consider the tangent stiffness method realisation main steps.

Assume that the joint displacement vector $\mathbf{u}_{v}$ and load level $\mathbf{F}_{v}$ at the beginning of the current step $v$ are known. Then the main iterations of v-th step can be carried out as follows:

1. Define the new load level of

$$
\mathbf{F}_{v+1}=\mathbf{F}_{v}+\Delta \mathbf{F},
$$

where $\Delta \mathbf{F}$ - the load increment vector;

2. Create the structural tangent stiffness matrix $\left[K_{\tau}\right]_{v}^{i}$ via assembling (combining) Eq (19) at the beginning of $i$-th iteration of the step $v$ and calculate its determinant. When it yields the negative magnitude, one can state that the structure is geometrically unstable and one must interrupt calculation. When the determinant magnitude is positive, one must create incremental equilibrium equation (20) for unbalanced joint force $\mathbf{F}_{c, v}^{i}$ (note, that for first iteration $\mathbf{F}_{c, v}^{i=1}=\Delta \mathbf{F}$ ):

$$
\left[K_{\tau}\right]_{v}^{i} \Delta \mathbf{u}_{v}^{i}=\mathbf{F}_{c, v}^{i} .
$$

3. Solve Eq (23) and determine the incremental values of global displacements at the end of $i$-th iteration of the current step $v$ :

$$
\Delta \mathbf{u}_{v}^{i}=\left(\left[K_{\tau}\right]_{v}^{i}\right)^{-1} \mathbf{F}_{c, v}^{i} .
$$

4. Calculate new joint displacements, adding the incremental values of displacement, being resulted from unbalanced nodal forces $\mathbf{F}_{c, v}$ to the ones, obtained in the previous iteration

$$
\mathbf{u}_{v}^{i}=\mathbf{u}_{v}^{i-1}+\Delta \mathbf{u}_{v}^{i} .
$$

5. Update the structure of new nodal geometry:

$$
\mathbf{x}_{v}^{i}=\mathbf{x}_{v}^{i-1}+\mathbf{u}_{v}^{i} .
$$

For this purpose calculate direction cosines of structural units, create direction cosine matrix $\left[T_{a b}\right]_{v}^{i}$ and fictitious matrix $[\bar{A}]_{v}^{i}$, obtained by assemblage of the elements equilibrium Eq (10) matrixes $\left[A_{a b}^{\prime}\right]_{v}^{i}$.

6. Define the incremental values of member end internal forces from (21) applying the equation

$$
\Delta \mathbf{S}_{a b}^{i}=\left[k_{\Delta}\right]_{v}^{i}\left(\left[A_{a b}^{\prime}\right]_{v}^{i}\right)^{T}\left[T_{a b}\right]_{v}^{i} \Delta \mathbf{u}_{a b, v}^{i}
$$

and create incremental nodal forces vector in global coordinate system:

$$
\Delta \mathbf{S}_{v}^{i}=\left[\Delta \mathbf{S}_{1, v}^{i}, \Delta \mathbf{S}_{2, v}^{i}, \ldots \Delta \mathbf{S}_{a b, v}^{i}, \ldots \Delta \mathbf{S}_{s, v}^{i}\right]^{T} .
$$

Here $s$ denote the total number of finite elements.

7. Calculate incremental values of initial nodal end forces of structural elements:

$$
\Delta \overline{\mathbf{F}}_{s, v}^{i}=[\bar{A}]_{v}^{i} \Delta \mathbf{S}_{v}^{i} .
$$

8. Define the vector of nodal forces increment

$$
\Delta \mathbf{F}_{s, v}^{i}=[C]^{T} \Delta \overline{\mathbf{F}}_{s, v}^{i},
$$

where $[C]$ - configuration matrix of local versus global displacements. It contains unit and zero components.

9. Determine total initial nodal forces and total member internal forces at the end of $i$-th iteration:

$$
\begin{aligned}
\mathbf{F}_{s, v}^{i} & =\mathbf{F}_{s, v}^{i-1}+\Delta \mathbf{F}_{s, v}^{i}, \\
\mathbf{S}_{v}^{i} & =\mathbf{S}_{v}^{i-1}+\Delta \mathbf{S}_{v}^{i} .
\end{aligned}
$$

10. Calculate unbalanced (compensating) joint forces given in $\mathrm{Eq}$ (22).

11. Check the prescribed convergence criterion in respect of previous iteration result:

$$
\mathbf{F}_{c, v}^{i}-\mathbf{F}_{c, v}^{i-1} \leq \text { eps? }
$$

If it is not satisfied, repeat the calculations of steps $1-10$.

Iterations are interrupted when the unbalanced forces $\mathbf{F}_{c, v}$ are found to be infinitesimally small ones and/or satisfy prescribed tolerance magnitude. Finally, the deformed configuration and the matrix of equilibrium equations of the structure $\left[A_{n}\right]=[C][\bar{A}]_{v}$, corresponding to the prescribed load $\mathbf{F}$, are obtained.

\section{Mathematical model of structure optimisation}

An optimisation problem of a structure described as a geometrically non-linear system is formulated as follows. The initial configuration of a structure, active external load and objective function of a problem (optimality criterion) are known. It is necessary to find a distribution of member cross-section areas $A$ (limit forces $S_{0}$ ) which would satisfy the optimality criterion of a minimum volume structure [5,9] when separate elements deform in an inelastic way. The constraints of the structure optimisation problem must necessarily include the conditions describing the actual SSS of a structure being in a state of plastic collapse. The SSS values are obtained from extreme energy principle of minimum dissipated power [5]. Structural requirements for stability of elements under limit slenderness are applied in order to guarantee limitations of structural deformations. The aforementioned conditions restrict a free development of plastic strains; therefore elements of an optimal structure induce both elastic and inelastic (plastic) deformation caused by residual forces $\mathbf{S}_{r}$ and residual displacements $\mathbf{u}_{r}$. Thus an optimal structure is in the state prior to plastic collapse. 
Thus the mathematical model of structure optimisation problem, including these limitations (using the FEM terminology), is as follows:

find

$$
\mathbf{L}^{T} \mathbf{S}_{0} \rightarrow \min ,
$$

subject to

$$
\begin{gathered}
{[\Gamma] \mathbf{S}_{0}-\left[\Phi_{c}\right] \mathbf{S}_{r} \geq\left[\Phi_{c}\right] \mathbf{S}_{e},} \\
{\left[A_{n}\right] \mathbf{S}_{r}=\mathbf{F}-\left[A_{n}\right] \mathbf{S}_{e},} \\
\mathbf{S}_{0} \geq \mathbf{S}_{0, c r}^{\min } .
\end{gathered}
$$

The values of elastic structural response $\mathbf{S}_{e}$ obtained in the last iteration of the last step of the second order analysis (30) are used in this mathematical model, ie $\mathbf{S}_{e}=\mathbf{S}_{v}^{i}$. In their turn, they are functionally dependent on structure parameters which are being optimised. A direct introduction of this functional dependence in the task of structure optimisation would substantially complicate both its formulation and its numerical implementation as well. Therefore the problem practically must be solved by iterations. The parameters of elastic response are calculated according to the obtained results of structure optimisation per each iteration. The iterative process is continued until it converges.

As it was mentioned above, the optimisation problem (31)-(34) requires presence of functional relations between the values of elastic response and optimised parameters of a structure, which, in their turn, determine values of limit forces, for instance, limit bending moments $M_{0}=\sigma_{y} W_{p l}$. Thus their relationship must represent a functional relation vs the cross-section area $A$. In case of standard rolled I-sections (eg of certain ones being employed in usual engineering practice), this relation can be approximated with required accuracy by ([9]):

$$
I=a_{1} A^{b_{1}}, \quad W_{p l}=a_{3} A^{b_{3}} .
$$

It is obvious that direct implementing the above relationships into formulation of constraints of the mathematical model (31)-(34) would result in the extremely complex expressions. Similar situation will occur when developing the matrix $\left[\Phi_{c}\right]$ of yield conditions. For example, in case of standard steel rolled I-sections the yield conditions for the $j$-th cross-section read:

$$
\left.\begin{array}{l}
M_{0 j}-\left|M_{j}\right| \geq 0, \\
M_{0 j}-\left|M_{j}\right| / 1,18-c_{j}^{+} N_{j} \geq 0, \\
M_{0 j}+\left|M_{j}\right| / 1,18+c_{j}^{-} N_{j} \geq 0 .
\end{array}\right\}
$$

The eccentricities $c^{+}$and $c^{-}$(relations between limit bending moment and limit axial force) are unknown in advance here. For tensile members they read:

$$
c^{+}=\frac{M_{0 j}}{N_{0 j}}=\frac{\sigma_{y} a_{3} A^{b_{3}}}{\sigma_{y} A}=a_{3} \cdot A^{b_{3}-1}
$$

and that for compressive members:

$$
c^{-}=\frac{M_{0 j}}{N_{c r j}}=\frac{\sigma_{y} a_{3} A^{b_{3}}}{\chi \sigma_{y} A}=\frac{a_{3}}{\chi} \cdot A^{b_{3}-1} .
$$

Here limit axial force (the design buckling resistance of a compression member) should be described by $N_{c r}=\sigma_{c r} A=\chi \sigma_{y} A$, where $\chi$ is the reduction coefficient dependent on the non-dimensional slenderness $\bar{\lambda}$ of a column ([16, 17]), which is determined as established by EN3 ([16]).

Most often the lower bound $S_{0, c r}^{\min }$ of the constructional requirements (34) is compatible with the minimum value of limit bending moment $M_{0, c r}^{\min }$. Considering the buckling condition of a compressed member according to the limit slenderness $\lambda_{\text {rib }}$ requirements [16, 17], it may be calculated using the expression:

$$
M_{0, c r}^{\min }=\sigma_{y} a_{3}\left(\frac{l_{b}^{2}}{a_{1} \lambda_{r i b}^{2}}\right)^{\frac{b_{3}}{b_{1}-1}} .
$$

The solution optimum volume structure problem (31)-(34) can be obtained via optimisation cycles. In each cycle the problem solution is determined in respect of the obtained second-order elastic response values. One obtains optimal values of limit forces of cross-sections and corresponding new $A, I$ and $c$. Then according to the obtained results of structure optimisation, the new parameters of elastic response for the next cycle are calculated applying the tangent stiffness method.

The main stages of structure optimisation cycle are:

1) to determine limit slenderness $\lambda_{\text {rib }}$ of elements of a structure as established by STR [17];

2) to select the initial vector of limit forces $\mathbf{S}_{0}^{p r}=\mathbf{S}_{0, c r}^{\min }=\mathbf{M}_{0, c r}^{\min }$ by to the formula (39) and to calculate corresponding initial values of members crosssection areas $A_{0}=\left(M_{0}^{p r} / \sigma_{y} \cdot a_{3}\right)^{1 / b_{3}}$;

3) applying the Newton-Raphson method, to identify the total member forces $S_{e}$, to obtain the deformed configuration matrix and create the matrix of equilibrium equations of the structure $\left[A_{n}\right]=[C][\bar{A}]_{v}$, corresponding to the prescribed load $\mathbf{F}$.

4) to determine values of members eccentricities $c^{+}=a_{3} \cdot A_{0}^{b_{3}-1}$ and $c^{-}=a_{3} \cdot A_{0}^{b_{3}-1} / \chi$;

5) to develop the matrix $\left[\Phi_{c}\right]$ of yield conditions;

6) to solve the problem of optimisation of linear mathematical programming (31)-(34) and, as a result, obtain new values of limit bending moments $M_{0}^{\text {new }}$;

7) to get new values of estimated cross-section areas of elements $A_{\text {new }}=\left(M_{0}^{\text {new }} / \sigma_{y} \cdot a_{3}\right)^{1 / b_{3}}$ using the optimisation results.

8) to verify the condition: whether absolute values of differences of limit bending moments are higher than the low positive number eps, ie verify whether $\left|M_{0}^{\text {new }}-M_{0}^{p r}\right|>$ eps? 
- if yes, then $A_{n e w}$ becomes $A_{0}$, and $M_{0}^{n e w}$ becomes $M_{0}^{p r}$ and the operation described in stage 3 is performed;

- if no, then the minimum volume structure is determined and next calculation operation is performed;

9) to create residual displacement influence matrix $[\bar{H}]$ and residual member forces influence matrix $[\bar{G}]$ by combining matrix of equilibrium equations $\left[A_{n}\right]$ and quasi-diagonal structure stiffness matrix $[K]$ of elemental flexural stiffness $E I_{j} / l_{j}$ and tension-compression $E A_{j} / l_{j}$ stiffness (here case of alike material, ie alike elasticity modulus $E$ is assumed). Then:

$$
\begin{gathered}
{[\bar{H}]=\left(\left[A_{n}\right][K]\left[A_{n}\right]^{T}\right)^{-1}\left[A_{n}\right][K]} \\
{[\bar{G}]=[K]\left[A_{n}\right]^{T}[\bar{H}]-[K] ;}
\end{gathered}
$$

10) to solve the structure, prior to plastic collapse, stress-strain state analysis mathematical model [11, 18]:

$$
\text { find } \begin{aligned}
& \left.\frac{1}{2} \lambda^{T}\left[\Phi_{c}\right][\bar{G}] \Phi_{c}\right]^{T} \lambda- \\
& \lambda^{T}\left(\mathbf{M}_{0}-\left[\Phi_{c}\left[[K]^{-1}[\bar{A}]^{T}[C][K]^{-1} \tilde{\mathbf{F}}\right) \rightarrow \max ,\right.\right.
\end{aligned}
$$

subject to

$$
\boldsymbol{\lambda} \geq \mathbf{0} \text {. }
$$

The solution of the quadratic programming problem (40)-(41) yields the Lagrange multipliers $\lambda$ magnitudes of the optimal structure, being in state prior to plastic collapse. Then the residual response values are determined, applying influence matrixes $\bar{H}$ and $\bar{G}$ (fixed in stage 9) by

$$
\begin{aligned}
& \mathbf{S}_{r}=[\bar{G}]\left[\Phi_{c}\right]^{T} \boldsymbol{\lambda}, \\
& \mathbf{u}_{r}=[\bar{H}]\left[\Phi_{c}\right]^{T} \boldsymbol{\lambda} .
\end{aligned}
$$

Having the abovementioned values of residual response, the actual internal forces and displacements, equivalent to an optimal solution, are determined.

\section{Numerical experiment}

For illustrating the possibilities of the proposed algorithm a structural optimisation problem of a sixteenstorey single-bay steel frame (Fig 4, a) subjected by vertical and lateral loads was solved. The geometry of the frame, the load application points, the load magnitudes, the distribution of the limit bending moment types $M_{0}$ are as shown in Fig 4, a. The total number of columns and beams in the frame is 48. Structural members are collected in 5 different groups of standard steel IPE sections, which limit bending moments are selected by the vector $\mathbf{M}_{0}=\left[\begin{array}{lllll}M_{01} & M_{02} & M_{03} & M_{04} & M_{05}\end{array}\right]^{T}$. The material physical properties are chosen as follows: yield limit $\sigma_{y}=235 \mathrm{MPa}$, elasticity modulus $E=210 \mathrm{GPa}$. Geometrical non-linear deformable behaviour is evaluated.

The created FEM discrete model is presented in Fig 4, b. It contains 50 nodes with $\mathrm{DOF}=112$ and combines two finite elements types, ie 32 columns elements assumed to be the compressive-tensile-flexural ones, the remaining 32 beams elements are flexural ones. Thus the discrete model contains 160 internal forces.

Modelling the necessary data for relationships (35) was performed for European I-beams corresponding to IPE sections. The required coefficients for relations of $I$ versus $A$ (in $\mathrm{cm}$ ) and $W_{p l}$ versus $A$ are presented in Table 1.

Table 1. Coefficients of relations (35)

\begin{tabular}{l|c|c|c|c}
\hline Section & $a_{1}$ & $b_{1}$ & $a_{3}$ & $b_{3}$ \\
\hline IPE & 0,7885 & 2,3210 & 0,8411 & 1,6572 \\
\hline IPE A & 1,0138 & 2,3093 & 0,9469 & 1,6595 \\
\hline IPE O & 0,9600 & 2,2335 & 0,9409 & 1,6106 \\
\hline IPE 750 & 386,51 & 1,1631 & 16,606 & 1,0977 \\
\hline IPN & 1,1698 & 2,1276 & 1,0227 & 1,5592 \\
\hline
\end{tabular}

Table 2. The optimum volume of 16-storey steel frame solution convergence per iterations

\begin{tabular}{c||c|c|c|c|c|c}
\hline Iteration & $M_{01}(\mathrm{kNm})$ & $M_{02}(\mathrm{kNm})$ & $M_{03}(\mathrm{kNm})$ & $M_{04}(\mathrm{kNm})$ & $M_{05}(\mathrm{kNm})$ & $\mathbf{L}^{\mathrm{T}} \mathbf{M}_{0}$ \\
\hline \hline 0 & 1000,000 & 1000,000 & 1000,000 & 1000,000 & 1000,000 & 249600 \\
\hline 1 & 1227,853 & 732,812 & 282,819 & 576,208 & 206,648 & 138504 \\
\hline 2 & 1360,077 & 703,673 & 232,997 & 578,199 & 246,625 & 144156 \\
\hline 3 & 1403,513 & 690,988 & 219,389 & 573,145 & 242,871 & 144375 \\
\hline 4 & 1419,203 & 687,594 & 216,892 & 571,755 & 244,252 & 144801 \\
\hline 5 & 1424,609 & 686,465 & 216,243 & 571,255 & 244,314 & 144925 \\
\hline 6 & 1426,487 & 686,114 & 216,104 & 571,085 & 244,388 & 144976 \\
\hline 7 & 1427,136 & 686,000 & 216,068 & 571,026 & 244,404 & 144994 \\
\hline 8 & 1427,360 & 685,962 & 216,059 & 571,006 & 244,410 & 145000 \\
\hline $\mathbf{9}$ & $\mathbf{1 4 2 7 , 4 3 7}$ & $\mathbf{6 8 5 , 9 5 0}$ & $\mathbf{2 1 6 , 0 5 6}$ & $\mathbf{5 7 0 , 9 9 9}$ & $\mathbf{2 4 4 , 4 1 2}$ & $\mathbf{1 4 5 0 0 1}$ \\
\hline \hline & $A_{1}\left(\mathrm{~cm}^{2}\right)$ & $A_{2}\left(\mathrm{~cm}^{2}\right)$ & $A_{3}\left(\mathrm{~cm}^{2}\right)$ & $A_{4}\left(\mathrm{~cm}^{2}\right)$ & $A_{5}\left(\mathrm{~cm}^{2}\right)$ & $V\left(\mathrm{~cm}^{3}\right)$ \\
\hline \hline $\mathbf{1 0}$ & $\mathbf{2 1 3 , 0 1 7 5}$ & $\mathbf{1 3 6 , 8 8 6 \mathbf { 0 }}$ & $\mathbf{6 8 , 1 7 1 ~ 8}$ & $\mathbf{1 2 2 , 5 4 4 1}$ & $\mathbf{7 3 , 4 3 8 \mathbf { 4 }}$ & $\mathbf{2 9 3 1 3 1 0}$ \\
\hline \hline & 282,96 & 177,36 & 86,43 & 148,84 & 86,08 & 3682500 \\
\hline
\end{tabular}




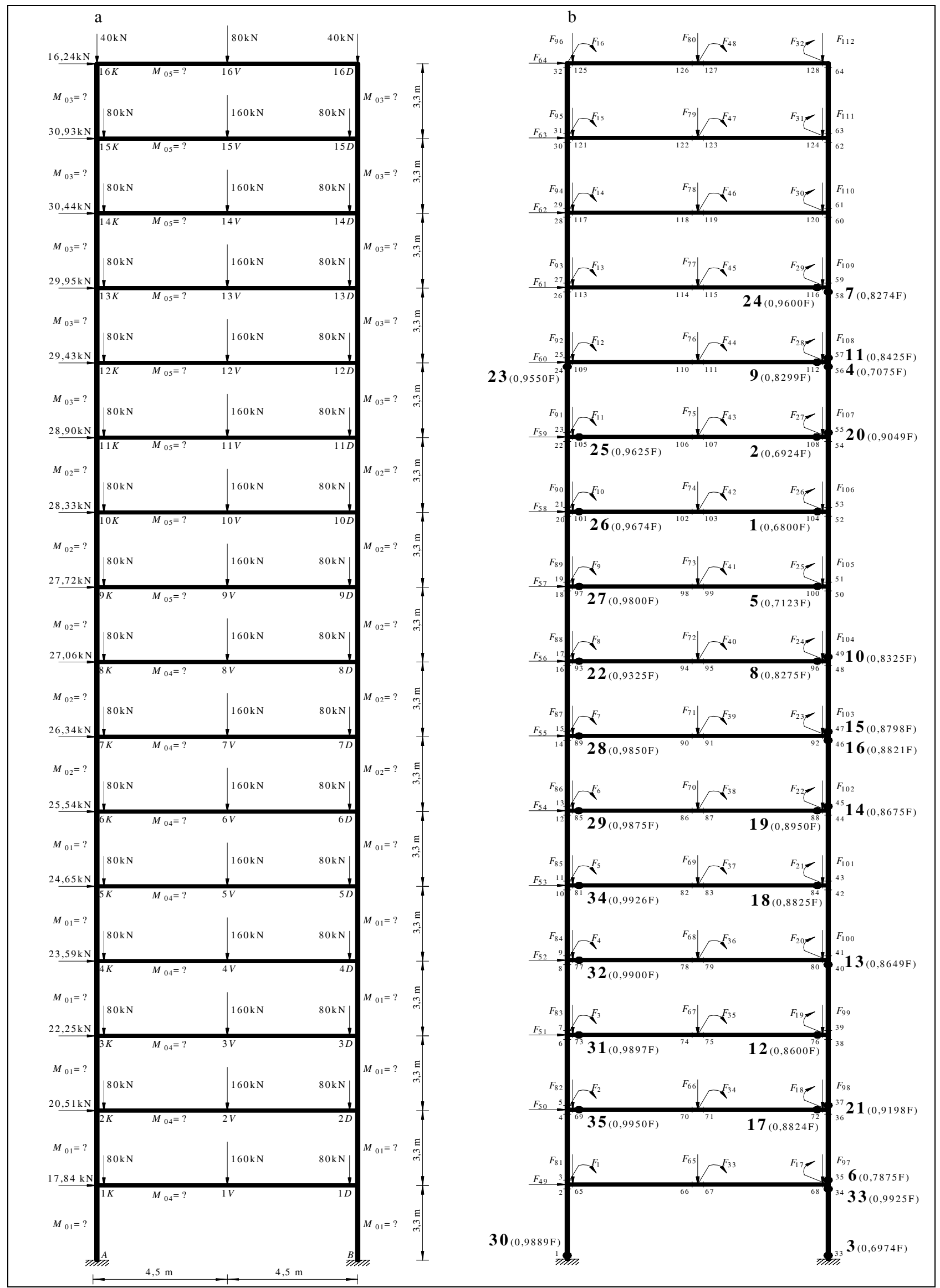

Fig 4. 16-storey steel frame and discrete model 
The constructive limitations of limit critical slenderness $\lambda \leq \lambda_{\text {rib }}=120$ in respect of optimised column members were introduced. The buckling length $l_{b}$ was determined according to requirements as established by STR ([17]). The admissible lower bounds of limit bending moments in each optimisation were identified for each optimisation cycle. Here expression (39) based on the buckling condition was employed. No structural requirements in respect of minimum slenderness values of beams have been introduced.

The design history is presented in Table 2. The optimum design was obtained per 9 iterations. Due to the obtained optimal distribution of the limit moments (see the 9 row of Table 2), the optimal cross-section areas of frame members were chosen. The structural minimum volume is $2931310 \mathrm{~cm}^{3}$. They are presented in the 10-th row of the same Table.

A reliability of designed structure behaviour was verified by solving the SSS evaluation problem (40)-(41) for the designed optimal frame. Analysis of structural behaviour during the loading history was performed. Fig 4, b illustrates positions of plastic hinges in order of appearance due to the load parameter magnitude (denoted in the parentheses). Note that the first plastic hinge appears at the load multiplier $0,68 F$, while the last, the 35-th, appears at the load multiplier 0,995 F. The extreme horizontal linear displacement located at the top storey varies from 34,05 cm (1-st plastic hinge) till 107,46 cm (35-th plastic hinge).

The optimum design of the same frame accounting linear elastic behaviour and allowable stress limit of $165 \mathrm{MPa}$ was obtained per 7 iterations (see the last row of Table 2). The minimum volume was obtained of $3682500 \mathrm{~cm}^{3}$, which is $25,6 \%$ more than the one obtained via the non-linear design.

\section{Conclusions}

The mathematical model and design algorithm is developed for geometrically non-linear structure crosssectional optimisation taking into account inelastic strains in the state prior to plastic collapse. The algorithm is obtained by coupling the extreme energy principle of minimum dissipated power and mathematical programming theory in concert with a large displacement analysis.

During iterative calculus procedures the design parameters are defined by means of non-linear analysis, applying a tangent stiffness computational procedures.

The performed numerical experiment of 16-storey steel frame optimisation under presence of stress and stability constraints illustrates the efficiency of proposed algorithm.

It has been shown that evaluation of physical and geometrical non-linearities in the optimal structural design leads as well as to the closer structural behaviour description comparing with an actual one, as to the minimisation of material resources for the optimal solution ensuring exploitative structural reliability.

\section{References}

1. KARKAUSKAS, R.; NORKUS, A. Truss optimization under stiffness, stability constraints and random loading. Mechanics Research Communications, 2006, 33(2), p. 177-189.

2. MANICKARAJAH, D.; XIE, Y. M.; STEVEN, G. P. Optimum design of frames with multiple constraints using an evolutionary method. Computers \& Structures, 2000, 74(6), p. 731-741.

3. KARKAUSKAS, R.; NORKUS, A. Optimization of geometrically non-linear elastic-plastic structures under stiffness constraints. Mechanics Research Communications, 2001, 28(5), p. 505-512.

4. BELYTSCHO, T.; LIU, W. Nonlinear finite elements for continua and structures. John Wiley \& Sons Ltd., 2000. $300 \mathrm{p}$.

5. ČYRAS, A.; BORKOWSKI, A.; KARKAUSKAS, R. Theory and methods of optimization of rigid-plastic systems. Vilnius: Technika, 2004. 354 p.

6. MARLET, R. T.; ARORA, J.S. Survey of multi-objective methods for engineering. Structural and Multidisciplinary Optimization, 2004, 26(6), p. 369-395.

7. SOH, C. K.; CHAN, T. K. Numerical method for lowerbound solution of the rigid-plastic limit analysis problem. Journal of Engineering Mechanics, 2001, 127(11), p. 1075-1081.

8. BAYRAK, O.; SHEIKH, S. A. Plastic hinge analysis. Journal of Structural Engineering, 2001, 127(9), p. 1092-1100.

9. SAKA, M. P.; HAYALIOGLU, M. S. Optimum design of geometrically non-linear elastic-plastic steel frames. Computers \& Structures, 1991, 38(3), p. 329-344.

10. HAYALIOGLU, M. S. Optimum design of geometrically non-linear elastic-plastic steel frames via genetic algorithm. Computers \& Structures, 2000, 77(5), p. 527-538.

11. KARKAUSKAS, R. Optimization of Elastic-Plastic Geometrically non-linear light-weight structures under stiffness and stability constraints. Journal of Civil Engineering and Management, 2004, 10(2), p. 97-106.

12. ZHANG, Y. G.; LU, M. W. An algorithm for plastic limit analysis. Computer Methods in Applied Mechanics and Engineering, 1995, 126(3-4), p. 333-341.

13. SAKA, M.; KAMESHKI, E. Optimum design of unbraced rigid frames. Computers \& Structures, 1998, 69(4). p. 433-442.

14. MEEK, J. L. Computer methods in structural analysis. Chapman \& Hall, 1991. 498 p.

15. ZIENKIEWICZ, O.; TAYLOR, R. The finite element method. Oxford: Butterworth-Heinemann, 2000, 5th edition. Vol 1: The Basis, 689 p.; Vol 2: Solid Mechanics, 459 p.; Fluid Dynamics, 334 p.

16. EC3. Eurocode No $3^{*}$ Design of Steel Structures, Vol 1, Nov 1990; Vol 2, July 1990.

17. STR 2.05.08:2005* Design of Steel Structures. Vilnius: 2005. (in Lithuanian).

18. KARKAUSKAS, R. Analysis of non-holonomic behaviour of geometrically nonlinear elastic-plastic framed structures. Mechanics (Mechanika), 1997, 4(11), p. 11-16. 
TAMPRIAI PLASTINIŲ GEOMETRIŠKAI NETIESINIŲ KONSTRUKCIJŲ, NEPASIEKUSIŲ VISIŠKO PLASTINIO SUIRIMO, OPTIMIZACIJA

\section{R. Karkauskas}

\section{Santrauka}

Plètojamas geometriškai netiesinių konstrukcijų strypų skerspjūvių optimizacijos uždavinio matematinis modelis ir skaičiavimo algoritmas, ịvertinantis netampriąsias deformacijas iki jos visiško plastinio suirimo. Algoritmas sudarytas naudojant ekstremini energijos disipacijos greičio minimumo principą ir matematinio programavimo teoriją gana didelių deformacijų analizei. Disipacinių savybių i̇vertinimas lemia reikšmingą laikomosios galios rezervo sumažinimą optimalios tamprios būklès konstrukcijos atžvilgiu. Eksploataciniai reikalavimai apima stiprumo ir stabilumo apribojimus. Uždavinys sprendžiamas iteracijų būdu, nes tampraus atsako dydžiai yra veikiami optimizuojamų konstrukcijos parametrų. Naudojama antros eilès netiesinė analizė grindžiama tangentiniu standumo metodu. Atliktas 16 aukštu plieninio rèmo, naudojant standartinius profilius, optimizacijos skaitinis eksperimentas.

Reikšminiai žodžiai: optimizacija, tampriai plastinẻ konstrukcija, geometrinis netiesiškumas, geometrinis standumas, tangentinio standumo matrica, plastinis suirimas.

Romanas KARKAUSKAS. Professor, PhD. Dept of Structural Mechanics, Vilnius Gediminas Technical University. Author and coauthor of 2 monographs, 2 manuals and over 90 research articles. Research interests: elasticplastic analysis and optimisation of structures, including physical and geometrical non-linearities, numerical methods in structural mechanics. Lithuanian State Research Prize Laureate (1993). 